\title{
Tres siglos de cuentística santiaguera (1830-2018): estéticas, obras y autores principales ${ }^{1}$
}

\author{
Ronald Antonio Ramírez Castellanos \\ Doctor en Ciencias Literarias \\ Universidad de La Habana, La Habana, Cuba \\ https://orcid.org/0000-0001-9015-0368 \\ ronaldantonio.ramirez@fenhi.uh.cu \\ Iván Gabriel Grajales Melián \\ Doctor en Ciencias Literarias \\ Universidad de Oriente, Santiago de Cuba, Cuba \\ https://orcid.org/0000-0002-4163-112X \\ ivang@uo.edu.cu
}

\section{Resumen}

Este artículo de investigación aporta un estudio de la cuentística santiaguera desde la etapa colonial hasta el presente. Se trata de una zona preterida dentro de los estudios literarios cubanos, generalmente enfocados, por la historiografía en la Isla, desde una perspectiva habanocentrista. El análisis de contenido y el enfoque historiográfico permite dilucidar los autores, obras y estéticas fundamentales que distinguen al proceso de génesis, desarrollo y consolidación del género en tres períodos: el colonial, el republicano neocolonial y la etapa revolucionaria. Los presupuestos que movilizan esta práctica escritural en la región pueden ser tenidos en cuenta, desde la historiografía literaria, para establecer contrapunteos con las experiencias ideoestéticas del género en Cuba y Latinoamérica.

Palabras clave: Autores; Cuba; cuentística santiaguera; genero; habanocentrista.

\section{Three centuries of Santiago de Cuba's short story (1830-1918): main aesthetics, texts and authors}

\section{Hbstract}

This research article contributes to the study of Santiago de Cuba's short story from the colonial period until today. This is a zone pretermitted within the Cuban literary studies, generally focused, by the literary historiography, from a havanocentrist perspective. The content analysis and the historiographic approach allows to elucidate authors, texts and main aesthetics that distinguish the process of origin, development and consolidation of this literary genre in three periods: the colonial, neo-colonial/republican and revolutionary. The

1 Procedencia del artículo: Este artículo hace parte de un interés académico colectivo. 
basics that characterize this writing practice in the region can establish counterpoints with the ideo-aesthetics experiences of the genre in Cuba and Latin America.

Keywords: Authors; Cuba; Cuba's short story; genre; havanocentrist.

Recibido: 02 de septiembre del 2019. Hprobado: 12 de febrero del 2020

Artículo de revisión

https://doi.org/10.25100/poligramas.v0i50.10652

\section{¿Cómo citar este artículo en MLH? - How to quote this article in MLA?}

Ramírez Castellanos, Ronald Antonio y Iván Gabriel, Grajales Melián. "Tres siglos de cuentística santiaguera (1830-2018): estéticas, obras y autores principales" Poligramas 50 (2020): n. pag. Web. Fecha de acceso (día, mes en mayúscula y abreviado, y año).

\section{Preliminares}

Desde el período colonial hasta la etapa contemporánea, la ciudad de Santiago de Cuba ha sido una plaza cultural importante para el desarrollo de la práctica literaria. La prevalencia del enfoque habanocentrista en el recuento historiográfico de la literatura cubana apenas ha tenido en cuenta la obra de autores de esta región, con expresiones identitarias locales, en muchos casos aportadoras al proceso de gestación, desarrollo y consolidación del hecho literario en la Isla. Después de la poesía, la narrativa, en particular la cuentística, ha sido el género por excelencia mediante el cual los círculos intelectuales santiagueros encontraron una forma expedita para vehicular sus inquietudes estéticas; se trata de un corpus textual, para nada despreciable, de calidades y tipologías diversas que nutrió las vertientes del cuento cubano, desde su surgimiento hasta el periodo actual.

Este artículo de investigación tiene como objetivo el estudio de esa zona de interés en el campo de la narrativa cubana y santiaguera en particular, con la finalidad de contribuir a la visibilización de una literatura preterida; determinar las estéticas, obras y autores fundamentales que de alguna manera han tenido su incidencia en la gestación del cuento cubano y sus aportes al mapa literario latinoamericano, sin pretensiones de exhaustividad; impacta en la necesidad de establecer las coordenadas para un ulterior proceso de escritura de la historia de la literatura en la región, todavía ausente, desde los presupuestos metodológicos de las ciencias literarias. 
Se asumen los preceptos teóricos sedimentados para el estudio del cuento (Beristáin 129; Marchese y Forradellas 84; Cuddon 815 y Childs \& Fowler 217): relativa brevedad, escasez de personajes, estéticas multiaspectuales en los planos composicionales y estilísticos, concreción, tema único, la capacidad de atrapar al lector en los inicios de la narración y el desenlace inesperado, tipologías del narrador y manejo del punto de vista, etc., por solo mencionar algunas de las pautas más importantes. Tratándose de una pesquisa que abarca un amplio periodo en el tiempo histórico, ha sido útil la división del estudio en tres etapas fundamentales: periodo colonial decimonono, desde la aparición de los primeros textos narrativos escritos por un autor santiaguero hasta el fin del dominio colonial en la Isla (1830-1898); republicano neocolonial (1902-1958) y revolucionario (1959-2018). Las estimativas circunscritas al contexto exclusivamente santiaguero no solo han sido un indicador para elaborar este análisis. Se consideró un parámetro selectivo mucho más amplio que incluye los siguientes criterios: 1) autores nacidos en la ciudad con una actividad literaria desarrollada en diversos ámbitos socioculturales; 2) autores de otras nacionalidades que radicaron en esta ciudad y desarrollaron, de modo temporal o definitivo, una amplia vida cultural y literaria con aportes consustanciales a la narrativa en el país y la región; y 3) los residentes permanentes en el territorio, con obras publicadas, por diversas razones, dentro y fuera del circuito editorial citadino. Este ejercicio de selección justifica el término Cuentística santiaguera y no en Santiago de Cuba, así como las inclusiones de autores como José María Heredia, Francisco Baralt, Tristán de Jesús Medina, Armando Leyva, Max Henríquez Ureña, Juan Francisco Sariol, los hermanos James Figarola, Juan Leyva Guerra, Augusto de la Torre, Amir Valle, por solo mencionar algunos.

De igual forma, si bien la calidad estética es un medidor importante a la hora de valorar autores y obras, no pretende con ello establecer las pautas para definir prácticas escriturales canónicas que, dentro del género, conforman a la literatura local. De ser así, se corre el riesgo de implantar un criterio elitista que no favorecerá a los estudios de la muy poco representada literatura santiaguera en la historiografía literaria nacional. Tampoco de ser partidarios de inclusiones paternalistas; antes bien, nuestro propósito consiste en mostrar, en su devenir histórico, el espíritu de aquellos precursores de antaño y hogaño que contribuyeron a definir la fisonomía de la patrilocalidad en sus múltiples esencias culturales, ya sea en la escritura de mayores relieves estéticos o en los instantes más logrados de las obras consideradas "menores". Tanto el extenso arco temporal que sustenta nuestro análisis como la amplia variedad de obras y autores nos obliga necesariamente a asumir, en el 
análisis de contenido, el enfoque historiográfico, ${ }^{2}$ aun cuando, por la particularidad de la obra o el autor implique un detenimiento mayor y un incentivo a la profundización en otros aspectos en trabajos posteriores con intereses investigativos más específicos.

Con todo, este artículo responde a la labor investigadora que durante varios años hemos desempeñado, desde la academia universitaria (Grajales y Ramírez), en torno al rescate y valoración del patrimonio literario en la ciudad de Santiago de Cuba. Por lo tanto, pretende llenar un vacío historiográfico sobre el tema y dar continuidad a los siempre útiles propósitos desplegados por estudiosos del género, en el ámbito historiográfico y crítico literario regional.

\section{Período colonial (1830-1898): orígenes y evolución del género}

A diferencia del género poético, la cuentística tuvo un surgimiento tardío en el campo cultural colonial santiaguero. El auge de las primeras publicaciones periódicas y revistas culturales con la introducción de la imprenta en la ciudad a inicios del siglo XIX propició la divulgación de una práctica literaria, todavía incipiente, que se gestaba en los círculos intelectuales de la ciudad. Sin embargo, los primeros relatos publicados por un santiaguero se deben a la autoría del conocido poeta José María Heredia y Heredia durante su exilio en tierra mexicana, considerado también el primer cubano iniciador del género. Se trata de un corpus de narraciones menores agrupadas con el título de Cuentos orientales en la revista mexicana Miscelánea, entre 1830 y 1832, que lamentablemente, en los recuentos históricos de la literatura cubana, los estudiosos del género en la Isla le han negado el carácter de textos fundacionales (Arias 189). El hecho se debe no solo a su publicación fuera del panorama insular, sino también a que, en la mayoría de los casos, se tratan de posibles traducciones no identificadas como tales (Arias 189). Apenas los textos "Abuzaid", "Historia de un salteador" y "Economía femenil" han logrado apuntalarse en antologías nacionales por el correcto y elegante estilo de su prosa que trasciende, en su interés temático, por su matiz costumbrista y su refinado sentido del humor (Bueno 69-80). Es importante explicar que los mayores aportes de Heredia radican en su poesía, no en su narrativa; sus relatos,

\footnotetext{
2 Emplear este enfoque implica, como se verá, las atenciones a una amplia variedad de textos y autores que ameritan, al mismo tiempo, un estudio más detallado. La carencia de este registro histórico obliga a este primer punto de partida. Hubiera sido útil apoyar los criterios de análisis con fragmentos que detallen las particularidades que se comentarán, al menos, de los principales textos narrativos. Sin embargo, los límites que exige la publicación de este artículo no permiten ese detenimiento específico en cada uno de los aspectos que señalarán. Sirva, pues, como un necesario incentivo a estudios de profundidad en autores y obras, según etapas, tendencias, estéticas, temáticas, entre otros tópicos de rigor.
} 
endebles incursiones en el género, tienen la validez del punto de partida de una práctica que experimentará una trayectoria ascendente, aunque bastante accidentada, a lo largo del período decimonónico santiaguero.

La preferencia por el género poético demorará la aparición de textos narrativos, casi siempre matizados por el afán anecdótico del articulismo de costumbres. La publicación de Ensayos literarios (1846) de Francisco Baralt, Pedro Santacilia y José Joaquín Hernández, es un ejemplo de ello. Se trata de un dossier de textos poéticos que incorpora relatos breves, viñetas, etc., y, hasta donde pudo pesquisarse, probablemente sea el primer texto editado en Santiago de Cuba que recoge una muestra de narraciones breves. Aunque algunas siguen la estética del artículo de costumbres; otras, como "Catalina", de Francisco Baralt, ya se apartan del aspecto documental y testimonial para vincularse a la introspección psicológica en el trazado de personajes. En esta línea del dossier literario aparece Murmurios del Cauto (1853), con relatos "La flor de Alayda" de Francisco Martínez Betancourt, un ejemplo de la presencia de la vertiente indianista en la literatura local, y "Sunsión" (Bueno 245-260), del bayamés radicado en Santiago Tristán de Jesús Medina, atendible por la dosificación de motivos y personajes que mantienen la vitalidad de una narración de tono epistolar. Por su parte, "Las piedras del fraile", de Francisco Baralt mixtura elementos románticos con el folklore oral.

En 1868, pocos meses antes del inicio de la lucha insurreccional contra España, Emilio Bacardí Moreau, más conocido por sus novelas históricas y cuentos infantiles en el lapso republicano, publica en dos partes, en la revista Oriente, su relato "El Lázaro" (Grajales y Ramírez 80-89), texto que centra su historia en la agónica existencia de un joven leproso que finalmente muere en brazos de su progenitora, sin que esta sea incapaz de impedir, impotente y desesperada, el trágico desenlace. De este lapso (1830-1868) son escasos los textos localizados; ${ }^{3}$ sus calidades, desde Heredia hasta las narraciones de iniciación de Bacardí, pueden considerarse como fundacionales de una práctica que no logra encausar todavía la madurez necesaria. Por lo regular, el tono anecdotario, con algunas inmersiones en lo psicológico en el diseño de personajes, evidencia el predominio de un romanticismo insustancial que entrecruza la visión costumbrista del entorno, la prosa románticolegendaria, en algunos casos, con inmersiones históricas en el tema indianista. Como nota

\footnotetext{
${ }^{3}$ Es probable que autores locales desconocidos, no mencionados aquí, hayan publicado alguna que otra narración, pero la ausencia de otros números en los principales archivos bibliotecarios de la ciudad, debido al alto grado de deterioro de la revista, nos impide elaborar un balance de ese registro al menos en la etapa.
} 
peculiar, se privilegia el tema del amor en relatos que tienen casi siempre de protagonista a la mujer, pues estas narraciones estaban dedicadas en su mayoría al público femenino.

Resulta prácticamente nula la producción literaria en Santiago de Cuba durante el periodo 1868-1878 debido al estallido de la primera contienda independentista contra España que tuvo, sobre todo al Departamento Oriental de la Isla, como principal escenario del conflicto bélico. La instauración de la censura de prensa y los límites impuestos a las publicaciones periódicas culturales que vieron cercenadas sus posibilidades de expresión y divulgación, representó una merma significativa para la producción intelectual local. En el periodo de entreguerras, sobre todo a partir de 1880 y hasta 1894, la actividad literaria en Santiago se revitaliza en las nuevas revistas culturales y publicaciones periódicas, los medios por excelencia en el devenir histórico del género. Hasta el período finisecular el cuento mantendrá su genuina vocación anecdótica, un definido propósito ético, aun cuando todavía es notable una persistente inmadurez en su estructuración ficcional. Nutrido de tópicos proporcionados por el romanticismo, surgen escasas pero apreciables muestras. La generación de escritores de El Álbum, la revista cultural publicada en Santiago de Cuba entre 1892 y 1893, que a diferencia de su predecesora El Mercurio (1882-1885) fue más afín al desarrollo de la poesía romántica local, le otorgó mayores potencialidades al espectro narrativo en sus páginas. Francisco Ortiz, muy conocido por el éxito de su novela Misterios de Cuba (1892), rubrica en varios números de El Álbum su relato "La loma del cascabel" (Grajales y Ramírez 102-118), texto ambientado en el Santiago de la conquista española (a inicios del siglo XVI) y que, al estilo de otras narraciones dentro de la línea nativista o indigenista, transparenta un mayor acabado en el trazado psicológico de sus personajes y un tratamiento más eficaz del tema. En 1895, se edita Bocetos y perfiles. Cuentos de la vida militar (1985), el primer volumen que reúne un conjunto de relatos de la autoría del desconocido Luis Romero Aguirre, al parecer, un peninsular asentado en la región o santiaguero hispanófilo. Quizás sea este libro un precursor de la vertiente histórica centrada en el tema de la contienda independentista desde la perspectiva del personaje militar español. Sus cuatro relatos del cuaderno "Rosa pálida", "Gardenia”, "Abrojos" y "Zarza mora”, resaltan por la caracterización del contexto citadino durante los primeros meses del estallido insurreccional y proporcionan un punto de vista que transparenta la filiación ideológica del autor en relación a los hechos históricos narrados.

También de este período, autores nacidos en Santiago de Cuba, pero radicados fuera del territorio, como Enrique Hernández Miyares y Diego Vicente Tejera, aportan textos narrativos de mayores relevancias estéticas. Tejera cultiva el cuento fantástico con "Julio 
Ramos" (Bueno 269-275), en el estilo de Poe y sus figuras fantasmagóricas; Miyares, por su parte, también inspirado en esta vertiente, pero menos apegada al suspense y con marcado acento en la crítica sociopolítica, escribe "La función de gala" (Bueno 289-293), atendible por su mixtura fantástico-histórica en la simulación de un ambiente fastuoso durante la celebración de un futuro aniversario de la independencia nacional. En este relato, la certera predicción de Miyares avizora el cinismo politiquero que caracterizará a la naciente República. En la revista La Habana Elegante, donde laboró durante años y de la cual fue su director, publicó otros relatos como "El cazador", "Peso del Oro" y "Dos viajes" (Romero C. 124-127) que de alguna manera evidencian el interés de este escritor por el relato breve, aunque sus mayores aportes se ubiquen en la poesía romántica cubana de fin de siglo.

\section{Período republicano neocolonial (1902-1958): el camino a la madurez}

Con el cese de la ocupación norteamericana y la capitulación del dominio colonial en la Isla, el lapso republicano, iniciado el 20 de mayo de 1902, implicó para Santiago de Cuba una restauración del escenario sociopolítico que contribuyó, de cierta forma, a la reapertura de la actividad literaria y cultural. Como en la etapa colonial, las diversas formas de expresión de la literatura, en particular el cuento, continuarán sirviéndose, esta vez con mayor difusión, de las publicaciones seriadas de nuevo tipo. En las páginas de Cuba Literaria (1904-1905), Ilustración cubana (1906-1907), Revista de Santiago (1907), Oriente literario (19101913), Actualidades (1920-1922), Luz de Oriente (1922-1924), Revista de Oriente (1928-1931), Azul (1945-1948), Orientación social (1951-1960), por solo mencionar algunas, convergerán los distintos adentramientos estéticos de las nuevas promociones de escritores en la región.

La Revista de Santiago convocó al primer certamen literario dedicado exclusivamente al cuento, en el cual resultó ganador "La campana de Tempú", de José G. Pujadas. Este relato, centrado en la línea de evocación histórica, introduce por primera vez el tema de la esclavitud, poco abordado en la narrativa local, con un manejo discretamente acertado de la caracterización realista de ambientes. José Manuel Poveda, más conocido por su invaluable legado poético, inicia sus incursiones narrativas en publicaciones de La Habana, Santiago y Manzanillo. Sus potencialidades estéticas en el género quedaron truncas por su afán anecdotario y el influjo de lo poético del cual no pudo sustraerse, a pesar de la fluidez y elegancia de su prosa que abordó con originalidad los conflictos existenciales de la conducta humana. En relatos como "Una muerte increíble" mezcla elementos fantásticos 
propios de la filiación modernista en no pocos casos expresivos de un pesimismo que visibiliza la nota irónica y la burla en la caracterización de personajes y ambientes.

En 1913, con sorprendente éxito de venta y crítica, Gastón B. Hernández publica Brotes de otoño, con una segunda edición ampliada al año siguiente. De los 25 cuentos de este volumen que entremezcla la fábula y el didactismo con la intención de acercarse al público infantil, resalta "Vanidad póstuma", un relato que muestra, con sentido moralizante, las amargas experiencias de la vida humana. Las escasas incursiones de Héctor Arístides Poveda en el género tienen su legado en el relato "La venganza de Juan Tudela", que sigue la tradicional vertiente histórica en su recuento de las luchas independentistas (Bahr, Cuentistas... 9)

La estética modernista es perceptible en autores que se inclinan por el tratamiento de temas fantásticos, algunos vinculados a sus prácticas religiosas y filosóficas como el animismo, la masonería y el esoterismo. Por lo regular, se trata de autores noveles en el género, pues hasta ese momento sus experiencias escriturales abarcaban zonas tan diversas como la poesía, la dramaturgia o la crónica periodística. Por ejemplo, los relatos de Arturo Clavijo Tisseur incluidos en la sección "Narraciones ingenuas" de su poemario Consagración eterna. Poesías y prosas (1920), "Los vampiros del Fuerte", "Miosotis Almanzor", "Guillermina Baussi" y "A través del tiempo", todos de escasos relieves narrativos y lastrados por un trasnochado esteticismo romántico, aunque dos de ellos, "Los vampiros del Fuerte" y "A través del tiempo", resultan pioneros en el tratamiento de la temática del vampirismo y los viajes témporo-espaciales en los cuentos de temas fantásticos. Del mismo modo, Las horas silenciosas (1920) de Armando Leyva Balaguer, con un estilo más depurado, aunque permeado de matices neorrománticos y estéril cursilería en el planteamiento de conflictos amorosos, consigue mayor interés en relatos como "Un suicidio" y "Un flirt extraño"; este último, el más conocido de sus textos en antologías sobre la experiencia fantástica del cuento cubano.

La influencia vanguardista se hace notar en Santiago de Cuba con la aparición de los Grupos Per se y H, cuyos programas estéticos fueron divulgados en las páginas culturales de La Independencia (1926) y Diario de Cuba (1928) respectivamente, los diarios de mayor difusión en la ciudad durante la época. A partir de ese lapso, y hasta 1958, el cuento santiaguero experimentará un salto estético cualitativo, sobre todo porque se aprecia un vínculo más estrecho entre el escritor y su entorno. El énfasis en la vocación realista y de orientación social no oblitera sin embargo la visión idílica, superficial y romántica en la praxis narrativa, que aún prevalece en la obra de algunos autores. 
En Válvulas de seguridad (1928), Constantino Castro demuestra interés por el aspecto ideoestético que, en sentido general, distinguió a la cuentística de temas urbanos, con particular escisión en las problemáticas de los sectores asalariados; su sentido crítico vertebra una denuncia, a veces irónica, contra la falsa moral de los líderes obreros (Bahr, Cuentistas... 9). Juan Francisco Sariol, de significativa incidencia en la vida cultural santiaguera durante las tres primeras décadas del XX, publica La muerte de Weyler (1931), cercano a la vertiente costumbrista-realista en su abordaje de la vida social de su Santiago natal, con una proyección ideológica identificada con las clases sociales marginadas. El cuento que nombra al libro, ${ }^{4}$ se inspira en personajes y asuntos tomados del pasado histórico para conformar una trama de madurez estética y un refinado tratamiento del humor negro como epicentro del conflicto narrativo.

Max Henríquez Ureña y Rómulo Lachatañeré exploran la tendencia negrista, pero desde perspectivas desiguales. El dominicano, quien había impulsado una intensa labor por el desarrollo cultural, artístico y literario en Santiago de Cuba, con "La conga se va..." de sus Cuentos insulares (1930), busca en las fiestas tradicionales carnavalescas de la ciudad un motivo para adentrarse en las costumbres y prácticas culturales de la comunidad afrocubana; Lachatañeré, en tanto, desde una óptica folklorista, en jOh, mío Yemayá! (1938) se nutre de las leyendas y poéticas mitológicas de la tradición oral yorubá para ficcionalizar sucesos e historias de vida de los dioses y el sistema mágico-religioso africano con un marcado propósito moralizador.

La obra de Emilio Bacardí Moreau, hasta entonces inédita, fue recogida de manera póstuma por su hija Amalia en los Cuentos de todas las noches (1950), un pequeño volumen precursor de la literatura infantil santiaguera y cubana en general. La vitalidad de sus relatos radica en el tono intimista de sus fábulas, ambientadas en entornos rurales, con un acucioso dominio del lenguaje popular, sobre todo de la norma oral santiaguera. Estas narraciones demuestran la madurez alcanzada por su autor en su experiencia como novelista (Via crucis 1914; Doña Guiomar 1916), hitos en la narrativa de esos años. Por su parte, Francisco Antonio Valhonrat y Villalonga en su relato "El ángel vengador" (Bahr, Cuentistas... 51-58), publicado en la Revista Oriental de Cuba en 1955 (Estrada 199), direcciona su interés en las problemáticas de la mujer como víctima de la violencia

\footnotetext{
${ }^{4}$ En 1948 publica Barrabás, otro volumen de narraciones que no ha sido posible localizar durante nuestra búsqueda en las principales bibliotecas del país.
} 
doméstica. Probablemente sea este uno de los textos pioneros en el abordaje crítico de estos temas, desde una perspectiva de género.

Por lo regular, se desconoce que el éxito posterior de José Soler Puig como novelista se debe a su primera experiencia como autor de relatos breves en revistas de Santiago de Cuba (Galería), La Habana (Carteles, Casa de Las Américas) y Guantánamo (Ahora) entre 1950 y 1961. Las temáticas y estéticas que particularizan a sus narrativas mayores - El año de enero (1963); El derrumbe (1964) y sus emblemáticas El pan dormido (1975), El caserón (1976). Un mundo de cosas (1982) y Ánima sola (1987) fundamentalmente, tienen su génesis en esos cuentos, compilados en una etapa posterior por la ensayista y también narradora local Aída Bahr. Sus rasgos temáticos y técnicos pueden resumirse de la siguiente manera: la preferencia por el tratamiento de temas universales como dramas pasionales, conflictos familiares casi siempre mediados por climas de violencia y tragedias ("Noche infernal", en Cúspide, 1939), alusiones a temáticas consideradas tabúes para la época como las relaciones incestuosas y el homosexualismo femenino ("Dos mujeres", Carteles, abril de 1956; la crítica social a la deshonestidad religiosa y prácticas laterales con fines de lucro ("El amuleto", en Carteles, 1960), la postura ateísta que desliza un despiadado cuestionamiento a la amoralidad y la filosofía judeocristianas ("El ciego", Galería, 1958), y al libre albedrío desde las relaciones paterno-filiales ("Dos viejos", en Antorcha, 1956); la creación de ambientes con acertada descripción realista de la precariedad y marginalidad de sectores desposeídos que no encuentran perspectivas de mejoramiento ante la grave situación socioeconómica imperante ("Cábala", Galería, 1958; "Dos ventanas", Galería, 1959) durante los regímenes dictatoriales de Gerardo Machado ("Mercado Libre", Casa de Las Américas, 1961). En cualesquiera de los casos, es posible distinguir un denominador común en la estética narrativa soleriana: su preocupación por la selección del narrador y el punto de vista para enunciar la historia que, desde "Los ciegos", lo coloca entre los cuentistas de primera línea en el país (Bahr, Los cuentos... 14); el perfeccionamiento del trazado psicológico de los personajes y la evolución de una narrativa que abandona el efectismo y el esquema convencional en el diseño de sus argumentos para potenciar hondura descriptiva más cercana al detalle realista; la depuración de un estilo narrativo que gana en síntesis y el manejo de la sugerencia en el desarrollo de las problemáticas abordadas en sus obras, así como el tratamiento del lenguaje popular en sus personajes tomados de sus experiencias personales de vida que reflejan, en resumen, las costumbres y prácticas sociales identitarias de su terruño natal (Bahr, Los cuentos... 19). 
La narrativa soleriana, en el proceso evolutivo del género en autores santiagueros, representa un parteaguas que avizora las primeras señales de un cambio, el perfeccionamiento de las técnicas narrativas, la madurez en las renovadas formas de expresión ideoestéticas que podrán apreciarse a partir del periodo republicano revolucionario.

\section{Período republicano revolucionario (1959-2018): consolidación y nuevas tendencias}

El triunfo de la Revolución cubana en 1959 implicó un proceso de profundas transformaciones en el orden cultural, las cuales intervienen en la concepción artísticoliteraria. La ruptura ideoestética con lo antes producido se traduce en las renovaciones y variantes estético-temáticas asimiladas de la producción precedente, que al mismo tiempo coadyuva al surgimiento de "una escritura cuya madurez genuina estaría vinculada a la consolidación del proceso revolucionario y sus contextos" (Garrandés, Panorama... 261). Dos líneas del cuento santiaguero quedan definidas desde las primeras décadas de esta nueva etapa: 1) la de autores nacidos en Santiago pero desde muy temprano residentes en La Habana, como Antón Arrufat y César López, quienes cultivarán una prosa imaginativa de temas extemporáneos, con evocaciones ficticio-testimoniales, o bien una prosecución de la poética del absurdo, con elementos neo-fantásticos, cercana a la línea cultivada por Virgilio Piñera y Ezequiel Vieta en el ámbito nacional; 2) la de los escritores que permanecen residiendo en Santiago que construirán un relato signado por la inmediatez, la urgencia de abordar temas vinculados a los nuevos procesos de transformación de la sociedad cubana y su proyecto revolucionario; esto es, la epicidad sustentada por un sentido ideológico en correspondencia con la estética del realismo socialista.

Estos nuevos escritores, nacidos antes de 1959, se iniciarán en el género en los espacios literarios diseñados desde la academia universitaria y otras instituciones culturales de la ciudad durante la década de los años sesenta. Juan Leyva Guerra, Rafael Soler, Efraín Nadereau Maceo y Alberto Serret, por solo mencionar algunos, publican esporádicamente relatos en las revistas Taller literario, Mambí y Cultura 64, entre otras, pero no será hasta los años setenta cuando sus obras, con los primeros cuadernos publicados, alcancen mayor visibilidad en tanto se adhieren a la denominada "narrativa de la violencia" (Arango 65; López F. 23). El término designa a la estética que centra como temática fundamental las luchas insurreccionales contra la dictadura de Batista, los atentados terroristas contra la 
Revolución en la década del sesenta, en especial, la invasión mercenaria a Playa Girón y la lucha de milicianos contra las bandas contrarrevolucionarias alzadas en las montañas del Escambray y Viñales con el apoyo de la CIA y el gobierno de los Estados Unidos; asimismo, la inserción de los jóvenes en la Campaña de Alfabetización, la Crisis de los misiles, la experiencia internacionalista en las guerras de liberación en tierras africanas, entre otros temas que responden a una teleología del mito épico de la nación en revolución. Esta tendencia narrativa conforma una tradición que puede rastrearse en el ámbito insular desde 1965 hasta el decenio de los 80 del pasado siglo.

Entre los autores y obras santiagueros más importantes pueden citarse a Joel James Figarola, con su cuaderno Los testigos y otros cuentos (1972), que obtuvo el Premio 26 de julio convocado por el Ministerio de las Fuerzas Armadas Revolucionarias (Minfar). Este volumen, muy apreciado por la crítica literaria nacional, se destaca por su diestro manejo de la tensión narrativa, la crudeza en el retrato de ambientes dominados por el terror, la venganza contra las injusticias y crímenes de la dictadura batistiana, las contradicciones ideológicas en personajes construidos a partir de la propia experiencia autoral en la lucha clandestina de esos años ("Los testigos", "Oficio de funerario", "Miriam"). Un aspecto significativo del cuaderno es la inclusión del tema histórico sobre la guerra independentista ("Días de mayo"), que se nutre de los saberes investigativos de James Figarola respecto a la formación de la nacionalidad y la identidad cultural cubanas. De igual forma merece atención la obra de Juan Leyva Guerra. Su texto El soldadito rubio (1973), premiado en el concurso de cuento "Luis Felipe Rodríguez" de la Unión de Escritores y Artistas de Cuba (Uneac), ofrece el recuento épico de las luchas clandestinas en el contexto urbano santiaguero y en las montañas de la Sierra Maestra con un singular adentramiento en el mundo carcelario durante el batistato. En tales escenarios, el recurso del diálogo, fundamentalmente, le permite a su autor explorar tópicos referentes al desarraigo, la moral revolucionaria y los conflictos que generan, en determinados sujetos, su resistencia y adaptación al nuevo contexto sociopolítico de la Revolución.

Alfredo Reyes Trejo publica Memorias de una jornada (1966), de menor relieve estético, aunque con visibles aciertos estilísticos, y más tarde Los junteros (1977), una incursión trágica al mundo campesino republicano que impugna la injusticia social del antiguo régimen, con detalles realistas no solo en la descripción de la precariedad cotidiana, sino también en su apropiación, con desiguales resultados, del léxico popular de las zonas rurales. Su interés por la inmersión en la memoria histórica se prolongará hasta su cuaderno Diles así... y otros cuentos (1988), con una mayor propensión a dinamitar la estructura 
tradicional del relato con una tendencia a la fragmentación episódica, aunque transido de fórmulas narrativas al uso. La fuerza del hombre (1977) de Orlando Concepción, insiste con opacidad en la mirada épica a las labores de la zafra azucarera y su preocupación por preservar el entorno medioambiental contra los desastres naturales. José Antonio Grillo Longoria, en ¿Qué color tiene el infierno? (1975) incorpora las problemáticas históricas de la lucha contra bandidos de un modo epidérmico, aunque, con Los patos en el pantano (1976), (Premio de cuento "26 de julio" del Minfar), se ajusta en parte a la tendencia épica vigente, al recrear los nuevos conflictos ideológicos surgidos con el desarrollo del proceso revolucionario. Como temática novedosa, uno de sus relatos, "Lo demás son detalles", discurre en los motivos del exilio a los Estados Unidos y sus conflictos ideológicos en las familias cubanas. En ¿Qué te dijo Clarita? (1979) redita, sin éxito, aunque con nuevas composiciones narrativas, algunos de los relatos de su primer libro, mientras que en Entre fugas y despertares (1982) la insistencia en las temáticas que más ocupa a su obra no emprende la renovación conceptual ni estilística en su estética autoral.

En ese orden, los cuadernos de Rafael Carralero y Arnoldo Tauler López también participan de la narrativa de la violencia. De Carralero son los títulos Con el ojo en la mira (1978), anecdótico y abigarrado en su dominio del suspense para recrear el ajusticiamiento a los esbirros de la tiranía; El comienzo tuvo un nombre (1980), de menor esteticidad en su bosquejo del clandestinaje, el mundo de las milicias y la campaña de alfabetización; y Tiro nocturno (1986), de mayor ponderación en cuanto al uso del lenguaje narrativo, el diseño de situaciones, ambientes y personajes. Tauler López, con La sangre regresada (1978), se inspira en la experiencia militar cubana en la guerra por la liberación de Angola desde una perspectiva testimonial, presente, también, en su libro La cáscara del hombre (1979), cuya estructura intenta el recuento de las epopeyas de lucha antes y durante el contexto revolucionario. En Cuentos de Seboruco (1979), sus narraciones-viñetas comparten el tono anecdótico con lo mítico-legendario en su recuento histórico y la mirada épica incorpora matices simbólicos que alcanzarán en El caracol manchado (1987), su cuaderno posterior, una relativa notoriedad aunque escapa a pretensiones renovadoras.

Justo Esteban Estevanell, en Santiago: 39 grados sobre O (1980), prosigue la exaltación épica del clandestinaje en la década del cincuenta, con personajes acentuados por sus contradicciones psicológicas y los altibajos de la conducta humana en situaciones extremas de violencia e incertidumbre sociopolíticas. En la Viña del Señor (1984), (Premio de Cuento Casa de Las Américas), Augusto de la Torre insiste en el abordaje de estos temas con el empleo de técnicas narrativas en gran medida renovadoras, y una crítica social que 
reflexiona sobre las problemáticas en torno a la corrupción y la burocracia de la sociedad cubana de entonces. También de ese año aparece Del símbolo y otros cuentos (1984), de Rodolfo "Chany" Ventura Guerra, probablemente precursor de la microficción nacional y del tratamiento del tema migratorio como asunto para la cuentística, en particular el éxodo del Mariel (1980), un episodio de negativas trascendencias en el devenir histórico nacional. De su autoría es también Variaciones (1988), un corpus de relatos-viñetas lastrados por el tono anecdótico, a medio camino entre la alegoría y el símbolo en su observación del retablo social y sus problemáticas de circunstancias.

Rafael Castro Mosqueda, más conocido por sus novelas Rajayoga (1986) y Verónico (1987), obtiene el reconocimiento de Casa de Las Américas con No hay tiempo para ser muchacho (1984), apuntalando su adentramiento psicosocial al pasado neocolonial, con atmósferas asfixiantes tanto en contextos rurales como urbanos; mientras que Una noche de dos mundos (1986) de Wilkie Delgado Correa, se sumerge en las contiendas del pasado más reciente, las injusticias contra el campesinado y sus apremios generacionales, con el propósito de jerarquizar en su gramática argumental un sentido ideológico cercano a la narrativa de propaganda.

En sentido general, estos cuentistas enhebran una tradición literaria, dentro del realismo socialista, exponente de la ideología de la Revolución, ya sea en su mirada al pasado de luchas por la liberación o al presente histórico, como forma de entender las transformaciones sociales experimentadas en esos años por la sociedad cubana. Las particularidades de estos cuadernos no se diferencian, con mucho, de las vertientes que identifican a las obras de los cuentistas del resto de la isla en el lapso. Si bien en su periodo inicial significó un modo de responder a una política cultural que privilegió la perspectiva ideológica de la Revolución triunfante, así como un cambio en el tratamiento de temáticas, asuntos que introdujeron renovaciones conceptuales y estilísticas, en su evolución la mayoría de estas poéticas autorales evidencian un estancamiento estético que lastró la calidad del género en el panorama literario regional. De ahí que la precariedad cualitativa le concede a la mayoría de estos textos un hálito de transitoriedad debido a "la repetición pasiva de procedimientos estilísticos y composicionales dentro de un lenguaje envejecido" (Garrandés, Panorama... 270).

Sin embargo, dentro de esta generación de autores, la obra de Rafael Soler, el hijo de José Soler Puig prematuramente fallecido en un accidente automovilístico aporta una "narrativa del cambio" (López F. 25; Arango 55) que sitúa "los conflictos fundamentales en la polaridad presente-pasado" (Arango 55). Los dos cuadernos de Soler hijo, publicados de 
manera póstuma, demostraron las potencialidades de este narrador en el género a escala insular. El primero, Campamento de artillería (1975), se estructura a partir de un conjunto de narraciones-viñetas que se adentran en el universo de la vida del miliciano movilizado para hacer frente a la futura agresión militar norteamericana, en el contexto de la Crisis de Octubre o Crisis de los Misiles (1962) que colocó a Cuba como posible escenario de un enfrentamiento nuclear. El manejo cuidadoso del lenguaje, desprovisto de toda retórica épica, permite el contrapunteo con la concepción psicológica de los personajes de sus narraciones, sujetos en constante polémica consigo mismo, desnudos en sus neurosis y conflictos que procuran la identificación y acoplamiento a un contexto de cambios sociales renovadores. Su segundo cuaderno, Noche de fósforos (1976), constituye un punto de giro en la literatura contemporánea santiaguera y cubana (Bahr 19; Arango 47-52; López F. 25; Garrandés, Los nuevos cuentistas 297). Precursora de una línea que se arraigaría en la siguiente década, la polémica "narrativa del deslumbramiento" (López F. 22-24; Garrandés, Los nuevos cuentistas 297), este libro proporciona la revitalización del género en medio de un panorama saturado de relatos heroicos o amargos sobre las luchas armadas revolucionarias. Soler oblitera el interés por la descripción de un ambiente potenciado por la violencia y las tensiones psicológicas - a diferencia de Campamento..., Noche de fósforos se centra en la campaña de alfabetización impulsada por el gobierno revolucionario en 1961- para pautar, desde la perspectiva de los personajes, una mirada que interpreta y busca la adecuación a un entorno que los deslumbra y les permite alcanzar su crecimiento y madurez. Se trata también de personajes cuyas conciencias y conductas permanecen en perenne conflicto (López F. 22-24), tensionadas por la asimilación de una realidad que en muchos casos los desborda. A juicio de Arango "(...) Soler fue el primero en reflejar en la narrativa cubana el tránsito entre los años de la inauguración y la euforia, y los del asentamiento y la consolidación (...)" (49).

A partir de los años ochenta, una nueva generación de escritores formados en el Taller literario "José María Heredia" de la ciudad santiaguera empieza a publicar en el periodo. Estos autores inciden en el proceso de ruptura con la estética anterior al privilegiar nuevos subgéneros dentro del relato, o bien, al seguirlas, introducen miradas novedosas al estilo de la obra de Soler. Alberto Serret incursiona en el relato de ciencia ficción con sus cuadernos Un día de otro planeta (1986) y Consultorio terrícola (1988), cercanos a los códigos estéticos que, dentro del subgénero, proceden de la literatura de los antiguos países socialistas de Europa del Este y de la extinta URSS, ampliamente divulgada en Cuba por esos años. Serret incorpora las problemáticas sociales de su contexto local, además de 
explorar tópicos de la cultura universal como el cine de Orson Welles y el psicoanálisis freudiano. De esta etapa, son también los textos de los hermanos Néstor y Roberto Leliebre, con Juegos prohibidos (1992) y Entre dos luces (1997), propensos al tratamiento de temas convencionales; también David González Gross, con Cuentos del Cauto (1988), libro menor, pero atendible por el empleo de sus técnicas narrativas.

De mayor importancia en cuanto a obras y autores en la década -los cuales, por lo regular, transitarán hasta la etapa contemporánea con cuadernos de nuevos relieves y calidades encomiables-, pueden citarse a Jorge Luis Hernández, Aída Bahr Varcárcel, José Mariano Torralbas, Amir Valle y Alberto Garrido. En El jugador de Chicago (1985), Hernández prosigue tardíamente la tendencia historicista en textos sobre las luchas estudiantiles en Santiago durante la década de los años cincuenta, las relaciones familiares en la vida de un joven alfabetizador, las problemáticas emocionales de la mujer en su incorporación a los cambios sociales propiciados por la revolución, "pero con una mirada oblicua, discreta, y casi evasiva que comporta una actualización" (Garrandés, Panorama... 281). Aída Bahr, aunque nacida en la provincia de Holguín, es tal vez la más importante escritora de narrativa entre los autores residentes en Santiago hasta el presente, con una obra consolidada por su dominio eficaz de las técnicas narrativas y su propósito de abordar temas actuales y de interés respecto al universo femenino. Su producción en el género resulta, tal vez, la más antologada, estudiada y traducida a diversos idiomas. Hay un gato en la ventana (1984), cuaderno de iniciación, polemiza en torno a las dificultades de la enseñanza del magisterio anterior a 1959 y los prejuicios sedimentados en el imaginario cultural cubano respecto a los desempeños de la mujer en la sociedad revolucionaria. Ellas, de noche (1989) y Espejismos (1998) discurren con acertado equilibro en el estudio psicológico de personajes femeninos, sus modos conductuales, conflictos sexuales, familiares y laborales, así como las contradicciones que generan la asimilación de una postura transgresora en el pensamiento hegemónico patriarcal. A partir de su segundo cuaderno, Bahr consigue alcanzar una madurez acaso sorprendentemente prematura y labrarse una voz propia dentro de la narrativa femenina cubana, con una estética realista enfocada mayormente en el universo de la mujer cubana, santiaguera, y sus contingencias (Capote 644). Ofelias (2007), (Premio Alejo Carpentier de Cuento 2007), hasta hoy su cuaderno de relatos más importante, vertebra siete cuentos en los cuales es posible establecer contrapunteos en las historias de vida de siete mujeres con problemáticas diversas -la violencia doméstica, la orientación sexual, conflictos en la adolescencia, laborales, psicológicos, etc.-, que tienen como denominador común la vulnerabilidad del 
cuerpo femenino en ambientes casi siempre opresivos, tanto en el espacio público como privado.

José Mariano Torralbas, Alberto Garrido y Amir Valle, integran el denominado grupo Seis del Ochenta, que intentó, con su manifiesto programático (Valle, Brevísimas... 56-63), revitalizar la actividad narrativa en el país, mediante el registro de temáticas polémicas, fórmulas narrativas renovadoras y la búsqueda de una identidad propia que implicaba un proceso de ruptura respecto a las formas de expresión del género, sedimentadas hasta ese momento. Torralbas incursiona con sus cuadernos En busca del eslabón (1989), La otra cara (1991), (Premio "El Caimán Barbudo" en 1987) y Señor de esperas (1995) en el universo de los cuentos sobre las becas estudiantiles, desde una perspectiva crítica contra el descalabro ético del sistema nacional de educación. Articula una denuncia al conformismo inercial de directivos docentes ("Consejo técnico"), el fraude académico ("Tín Marín" y "Confabulación en las estrellas"), el promocionismo estudiantil, las incomprensiones ante las relaciones amorosas entre alumnos y profesores ("Punto y aparte", "Punto final", "Entrecomillas" y "Un día antes del sábado"), los convencionalismos pedagógicos ("Tú"), las rupturas familiares por diferencias ideológicas que motivan el exilio a los Estados Unidos ("Domingo productivo"); cuentos que, en sentido general, fueron escritos antes de 1987 inspirados en su observación personal de ese contexto en su labor no solo como escritor sino también como maestro (Valle, Brevísimas... 94).

De los volúmenes El otro viento del cristal (1993); Nostalgia de septiembre (1994) y El muro de las lamentaciones (2000). Premio Casa de Las Américas de Cuento (1999), de Alberto Garrido, resaltan los relatos que tematizan el desequilibrio emocional de la moral ética revolucionaria en escenarios bélicos (la guerra de Angola), pero desde la perspectiva del individuo corroído por la fatalidad, la desesperanza, el estrés postraumático y la desilusión ante la incertidumbre de un futuro que ya no es promisorio sino incierto, vacío. La lucha por la supervivencia, el egoísmo, las individualidades fragmentadas en ambientes de hostilidad y muerte, son puestos en solfa para polemizar en torno a los dobleces de la condición humana en una sociedad socavada por el resquebrajamiento de los ideales revolucionarios. Desde esa mirada, sus narraciones en El muro... derivan en la insatisfacción del sujeto nacional y su descreimiento en una sociedad en crisis, incorporando un abordaje del erotismo sin vínculos pasionales.

Amir Valle, con mayores consistencias estéticas en sus novelas que en su cuentística, no escapa, sin embargo, al tratamiento de las convulsiones del panorama cubano en Tiempo en cueros (1988), Yo soy el malo (1989), En nombre de Dios (1990) y Manuscrito del 
muerto (2000), fundamentalmente, evolucionando desde un realismo desenfadado, casi anecdótico en sus relatos de iniciación, hacia una progresiva reflexión contestataria en torno a asuntos polémicos, en ocasiones, como en su último libro mencionado, hibridando las fronteras entre realidad y fantasía. Es importante aclarar que Valle, como Torralbas y Arrufat (¿Qué harás después de mí?, 1991; Ejercicios para hacer de la esterilidad virtud, 1997. etc.), publican sus obras fuera del contexto propiamente santiaguero, de modo que la naturaleza temática de sus relatos se aparta de la tradición de explorar ambientes, personajes y situaciones que sí distinguirán a escritores residentes en la ciudad como Jorge Luis Hernández, Aída Bahr y la nueva promoción de escritores nacidos a partir de 1970, que publicarán, fundamentalmente, en la primera década del siglo XXI.

La crisis económica que dio inicio al llamado "Periodo especial" en Cuba, luego de la desaparición del bloque de países socialistas en Europa del este y la URSS, incidió en el deterioro de la actividad literaria entre 1992 y 1998 en la ciudad; apenas solo estos narradores más conocidos tuvieron la posibilidad de publicar sus nuevas obras en las denominadas editoriales nacionales (Oriente, Unión, Letras Cubanas), con tiradas limitadas de sus ejemplares. Habrá que esperar a finales de los noventa para apreciar una relativa recuperación de la actividad literaria debido a las posibilidades de publicación en soporte papel que proporcionan los nuevos avances tecnológicos con la instalación de los sistemas Risograph en las cabeceras provinciales del país, una iniciativa propiciada por la dirección del Gobierno cubano que le otorgó mayor autonomía a la producción editorial en provincias. De esta manera, se intentó visibilizar la obra literaria de nuevos escritores, incluso los más jóvenes, que hasta ese momento no habían tenido la posibilidad de insertarse en el mercado editorial cubano.

Así, surgen los textos Hoja de ruta (1998) de Manuel Gómez Morales, su primer cuaderno en una entrada demorada al género narrativo, aunque pionero en la inclusión de temas escabrosos relacionados con las desigualdades sociales y los efectos negativos de la crisis en la región, entre estos la prostitución femenina; El último ángel de la memoria (1999) de Rubén Wong Subirat, sugerente en su experimentación cronotópica; Convite de cenizas (2002) y Tras la piel (2004) centrados en la exploración de las relaciones humanas en contextos diversos, sobre todo familiares, ambos de Argenis Osorio Sánchez; Antología de la síntesis (2005) de Osmar Álvarez Clavel; Gajes del oficio (2008) de Antonio Marino Fáez Leyva y Mímesis (2010) Carlos Luis López Vázquez. En resumen, la etapa finisecular estará dominada por autores con obras intermitentes y tardías (Álvarez Clavel, Marino Fáez); otras, desafortunadamente malogradas por la fatalidad de una muerte prematura 
(López Váquez), en tanto los trabajos de Jorge Labañino Legrá, Osmel Valdés Guerrero y Eduard Encina, principalmente, agrupados en la Asociación Hermanos Saíz del territorio, aparecen casi siempre dispersos en revistas u otras plataformas culturales locales o en antologías que ven la luz con el propósito de promocionar un corpus que no encuentra, todavía, una salida individual, propia de todo ejercicio de iniciación en el género.

De las dos primeras décadas del siglo XXI, la narrativa santiaguera parece consolidarse no solo con los textos de Bahr ya mencionados, sino también con la obra de nuevos narradores que, a nuestro juicio, por la calidad y el repunte temático-estilístico de sus textos, dominarán el espectro cultural y literario de la ciudad en los próximos años. Estos autores pueden dividirse en dos promociones esenciales: los nacidos entre 1974 y 1990 que publican a partir de los años dos mil, conocidos como los narradores locales de la Generación de los Años Cero; y los nacidos a partir de 1990 cuya obra comienza a publicarse, fundamentalmente desde el 2013. De la primera promoción vale indicar los cuadernos de Yunier Riquenes, a nuestro juicio el más importante de los jóvenes narradores residentes en Santiago con una obra ya consolidada y reconocida en el panorama insular. De él son sus textos La llama en la boca (2004), Quién cuidará a los perros (2007), Lo que me ha dado la noche (2007), La espalda marcada (2014) y Las coincidencias (2018); Gizeh Portuondo Vega Por el miedo al absurdo (2006) y Escape (2017); Rainer Gabriel Martínez Cascante Cambio de posición (2013) y Julio Jiménez Cinco perros y un ratón (2014). De la segunda promoción, más visible, César Guerrero y su cuaderno April Hill $(2018))^{5}$

La temática de los relatos de estos jóvenes autores, con una trayectoria en ascenso que ya comprende accésits, menciones y no pocos galardones en premios literarios locales y nacionales, ${ }^{6}$ discurre entre el abordaje intimista y familiar del entorno rural, con énfasis en los conflictos interpersonales y generacionales, y el tratamiento descarnado con tintes realistas del contexto urbano en su marginalidad, corrosión e inercia existencial, desde una mirada irreverente, desprejuiciada, crítica e irónica del descalabro insular, retratado desde una óptica documentalística que oscila entre un naturalismo-realismo sosegado y un

\footnotetext{
${ }^{5}$ Y una extensa lista de narradores que incluyen a Marisol Gómez Gálvez, Jorge Luis Lozano, Léster García Rondón, Enrique Matos Aguilera, Yulexis Ciudad, Arianna Naranjo Leonard, Herson Tissert, Aneyansis Bandera Nápoles, Miriaimy Breff Font, Orestes Martín Solís Yero, Yansy Sánchez, Eriakna "Eri (c)ka" Castellanos Abad, Ramón Muñiz Sarmiento, Nayra M. Simonó Veranes, Adela Rivas Cruz y Yolanda Aguirre Choy, sin cuadernos publicados, pero con textos ya conocidos en publicaciones periódicas culturales y en antologías o compendios narrativos en Cuba o el extranjero.

${ }^{6}$ Los narradores Rainer Gabriel Martínez Cascante (Gabriel Cascante) y Yunier Riquenes, por ejemplo, obtuvieron menciones en el prestigioso Concurso Iberoamericano de Cuento "Julio Cortázar" en 2018 y 2019 respectivamente.
} 
hiperrealismo grotesco, "sucio"; también el abordaje de temas extemporáneos en atmósferas de suspense, horror y humor negro en microrrelatos donde lo anecdótico supera toda posibilidad de detenimiento en los rizomas de la psicología humana. . Las nuevas tendencias del relato apuntan, por lo general, a la desautomatización de una escritura que privilegia el lenguaje y sus potencialidades de enunciación antes que lo argumental, con la exploración psicosocial de los personajes; el absurdo, lo fantástico, la sci-fi, la metatextualidad y los dilemas del sujeto ante el proceso artístico y la creación literaria; asimismo, un (ab) uso a veces descarnado de lo erótico-sexual en sus diferentes formas de expresión. En todos los casos, la hibridez posmoderna de la escritura postula una ruptura con las pretensiones de ideologización política que ostentaba, hasta los ochentas y poco más, el texto narrativo. De igual forma, las tipologías narrativas de estos cuadernos casi siempre se estructuran como piezas de continuidad que bien pueden funcionar como variantes de "cuentinovelas" o bien como ensayos de escritura que hacen gala de una esteticidad compleja, domeñadas por el punto de vista de un narrador ora esquizofrénico, ora convencional; que fractura las fronteras entre la narración, la descripción, el diálogo y las categorías témporo-espaciales, y violenta las situaciones en su propósito de tornarse escurridizo, inapresable, a los ojos del lector.

\section{Palabras finales}

¿Cómo evaluar el proceso de desarrollo de la cuentística santiaguera, desde su surgimiento hasta la etapa contemporánea, y cuáles sus aportes más esenciales al panorama literario cubano y latinoamericano en general?

El cuento, como parte de una narrativa que todavía amerita un estudio más abarcador -al campo de la novelística, por ejemplo-, surge en el período colonial de forma tardía en la etapa decimonona -a diferencia de la poesía-, con textos narrativos que se nutren de las fórmulas tradicionales al uso dentro de la estética romántica, sin muestras significativas de interés. No obstante, es posible advertir desde su surgimiento la marca distintiva de las narraciones locales: la intencionalidad documental del registro costumbrista que evoluciona hacia un afán identitario, revelador de la interacción del escritor con su entorno, sobre todo en los autores residentes en la ciudad. Con el influjo de las estéticas predominantes en la etapa republicana neocolonial -neorromaticismo, modernismo y algunas incursiones vanguardistas- se perfila una madurez estética que eclosiona, posteriormente, en las obras de las diferentes generaciones de escritores en el lapso revolucionario. Las 
heterogeneidades conceptuales y estilísticas de esos años apuntalan el afán historicista de los narradores locales, sus alineamientos y rupturas con los procesos que experimenta la isla en el orden sociopolítico y cultural.

Las aprehensiones, disconformidades, intereses temáticos se encausan en la hibridez de técnicas narrativas que siguen las tendencias estéticas actuales, signadas por el sello posmoderno que parece ser, hoy día, la pretensión del relato contemporáneo santiaguero en su búsqueda de la trascendencia en el mapa literario cubano y latinoamericano. Es necesario ahondar en las particularidades de las obras de autores como Jorge Luis Hernández, Aída Bahr, Amir Valle, José Mariano Torralbas, Alberto Garrido y la de los más jóvenes escritores como Yunier Riquenes, cuya relevancia para las letras regionales puede ofrecer zonas de interés respecto a la narrativa insular, escasamente efectuados hasta el presente en los actuales estudios historiográficos, desde las ciencias literarias.

\section{Referencias}

Álvarez Clavel, Osmar. Antología de la síntesis. Santiago de Cuba: Santiago, 2005. Impreso. Arango, Arturo. Reincidencias. Ciudad de La Habana: Abril, 1989. Impreso.

Arias, Salvador. "La narrativa del primer romanticismo (1820-1844)". Historia de la Literatura Cubana. Tomo 1. La Colonia: desde los orígenes hasta 1898. La Habana: Letras Cubanas, 2003. 188-212. Impreso.

Arrufat, Antón. Mis antagonistas y otras observaciones. La Habana: Ediciones R, 1963. Impreso.

Bacardí, Emilio. Cuentos de todas las noches. La Habana: Úcar García, 1950. Impreso.

Bahr, Aida, comp. Los cuentos de José Soler Puig. Santiago de Cuba: Oriente, 1999. Impreso.

Bahr, Aida, comp. De los cuentistas de ayer. Santiago de Cuba, Editorial Oriente, 1991. Impreso.

Bahr, Aida. Hay un gato en la ventana. La Habana: Letras Cubanas, 1984. Impreso.

Bahr, Aida. Rafael Soler: Ellas, de noche. La Habana: Letras Cubanas, 1989. Impreso.

Bahr, Aida. Espejismos. La Habana: Unión, 1998. Impreso.

Bahr, Aida. Ofelias. La Habana: Letras Cubanas, 2007. Impreso.

Baralt, Francisco. Las piedras del fraile. Tradición cubana del siglo XVIII. Santiago de Cuba: El Cubano Libre, 1910. Impreso. 
Beristáin, Helena. Diccionario de Retórica y Poética. México: Editorial Porrúa S.A, 1995. Impreso.

Bueno, Salvador, (comp.). Cuentos cubanos del siglo XIX. La Habana: Arte y Literatura, 1975. Impreso.

Capote, Zaída. "Panorama del cuento". Historia de la literatura cubana. La Revolución (1959-1988). Tomo III. La Habana: Letras Cubanas, 2008. 636-649. Impreso.

Carralero, Rafael. Con el ojo en la mira. Santiago de Cuba: Uvero, 1978. Impreso.

Carralero, Rafael. El comienzo tuvo un nombre. La Habana: Arte y Literatura, 1980. Impreso.

Carralero, Rafael. Tiro nocturno. La Habana: Letras Cubanas, 1986. Impreso.

Castro, Constantino. Válvulas de seguridad. Santiago de Cuba: Imprenta Matute, 1928. Impreso.

Castro Mosquera, Rafael. No hay tiempo para ser muchacho. Santiago de Cuba: Oriente, 1985. Impreso.

Childs, P. \& R. Fowler. The Routledge Dictionary of Literary Terms. London: Taylor \& Francis Group, 2006. Impreso.

Clavijo Tisseur, Arturo. Consagración eterna. Poesías y prosas. Santiago de Cuba: La Moderna Poesía, 1920. Impreso.

Concepción, Orlando. La fuerza del hombre. La Habana: Arte y Literatura, 1977. Impreso.

Cuddon, J.A. The Penguin Dictionary of Literary Terms and Literary Theory. Revised by C.E. Preston. England: Penguin Books, 1999. Impreso.

Delgado Correa, Wilkie. Una noche de dos mundos. Santiago de Cuba: Oriente, 1986. Impreso.

Estevanell, Justo Esteban. Santiago: 39 grados sobre O. La Habana: Letras Cubanas, 1980. Impreso.

Estrada, León. Santiago Literario. Santiago de Cuba: Oriente-Fundación Caguayo, 2013. Impreso.

Fáez Leyva, Antonio Marino. Gajes del oficio. Santiago de Cuba: Santiago, 2008. Impreso.

Garrandés, Alberto. "El cuento. Panorama de su desarrollo" Historia de la literatura cubana. La Revolución (1959-1988). Tomo III. La Habana: Letras Cubanas, 2008. 261283. Impreso.

Garrandés, Alberto. "Los nuevos cuentistas". Historia de la literatura cubana. La Revolución (1959-1988). Tomo III. La Habana: Letras Cubanas, 2008. 295-301. Impreso.

Garrido, Alberto. El otro viento del cristal. La Habana: Letras Cubanas, 1993. Impreso. 
Garrido, Alberto. Nostalgia de septiembre. Las Tunas: San Lope, 1994. Impreso.

Garrido, Alberto. El muro de las lamentaciones. La Habana: Casa de las Américas, 2000. Impreso.

Gómez Morales, Manuel. Hoja de ruta. Santiago de Cuba: Catedral, 1998.

González Gross, David. Cuentos del Cauto. Santiago de Cuba: Caserón, 1988. Impreso.

Grajales Melián, Iván y Ronald Ramírez Castellanos, comp. Narraciones en el tiempo. Antología. Santiago de Cuba: Caserón, 2015. Impreso.

Grillo Longoria, José Antonio. ¿Qué color tiene el infierno? La Habana: Arte y Literatura, 1975. Impreso.

Grillo Longoria, José Antonio. Los patos en el pantano. La Habana: Arte y Literatura, 1976. Impreso.

Grillo Longoria, José Antonio. ¿Qué te dijo Clarita? La Habana: Arte y Literatura, 1979. Impreso.

Grillo Longoria, José Antonio. Entre fugas y despertares. La Habana: Letras Cubanas, 1982. Impreso.

Guerrero, César. April Hill. Santiago de Cuba: Santiago, 2018. Impreso.

Henríquez Ureña, Max. Cuentos insulares. Santiago de Cuba: Archipiélago, 1930. Impreso.

Hernández, Gastón B. Brotes de otoño. Habana: Imprenta Militar de Pérez Hermanos, 1914. Impreso.

Hernández, José Joaquín, Francisco Baralt y Pedro Santacilia. Ensayos literarios. Santiago de Cuba: Cuba, 1846. Impreso.

Hernández, Jorge Luis. El jugador de Chicago. La Habana: Unión, 1985. Impreso.

James Figarola, Joel: Los testigos y otros cuentos. Ciudad de La Habana: Letras Cubanas, 1972. Impreso.

Jiménez Jardines, Julio. Cinco perros y un ratón. Santiago de Cuba: Santiago, 2014. Impreso. Lachatañeré, Rómulo. jOh, mío Yemayá! Manzanillo: El Arte, 1938. Impreso.

Leliebre, Roberto y Néstor Leliebre. Juegos prohibidos. Santiago de Cuba: Oriente, 1992. Impreso.

Leliebre, Roberto y Néstor Leliebre. Entre dos luces. Santiago de Cuba: Oriente, 1997. Impreso.

Leyva Balaguer, Armando. Las horas silenciosas. Santiago de Cuba: El Sol S.A, 1920. Impreso.

Leyva Guerra, Juan. El soldadito rubio. La Habana: Uneac, 1973. Impreso.

López, César. Circulando el cuadrado. La Habana: Ediciones R, 1963. Impreso. 
López Sacha, Francisco. Pastel flameante. La Habana: Letras cubanas, 2006. Impreso. López Vázquez, Carlos Luis. Mímesis. Santiago de Cuba: Santiago, 2010. Impreso.

Marchese A. y J. Forradellas. Diccionario de Retórica, Crítica y Terminología Literaria. $7 \mathrm{ma}$ ed. Barcelona: Editorial Ariel S.A, 2000. Impreso.

Martínez Cascante, Rainer Gabriel. Cambios de posición. Santiago de Cuba: Santiago, 2013. Impreso.

Martínez, Francisco. "La flor de Alayda". Murmurios del Cauto. Santiago de Cuba: Imprenta Miguel A. Martínez, 1853. 16-18. Impreso.

Osorio Sánchez, Argenis. Convite de cenizas. Santiago de Cuba: Santiago, 2002. Impreso.

Osorio Sánchez, Argenis. Tras la piel. Santiago de Cuba: Santiago, 2004. Impreso.

Portuondo Vega, Gizeh. Por el miedo al absurdo. Santiago de Cuba: Santiago, 2006. Impreso.

Portuondo Vega, Gizeh. Escape. Santiago de Cuba: Santiago, 2017. Impreso.

Reyes Trejo, Alfredo. Memorias de una jornada. La Habana: Granma, 1966. Impreso.

Reyes Trejo, Alfredo. Diles así.., y otros cuentos. Santiago de Cuba: Oriente, 1989. Impreso.

Reyes Trejo, Alfredo. Los junteros. La Habana: Unión, 1977. Impreso.

Riquenes García, Yunier. La llama en la boca. Granma: Bayamo, 2004. Impreso.

Riquenes García, Yunier. Lo que me ha dado la noche. Santiago de Cuba: Oriente, 2007. Impreso.

Riquenes García, Yunier. Quién cuidará a los perros. Santiago de Cuba: Oriente, 2007. Impreso.

Riquenes García, Yunier. La espalda marcada. La Habana: Letras Cubanas, 2014. Impreso.

Riquenes García, Yunier. Las coincidencias. Matanzas: Matanzas, 2018. Impreso.

Romero, Cira, comp. Los cuentos de La Habana Elegante. La Habana: José Martí, 2014. Impreso.

Romero Aguirre, Luis. Bocetos y perfiles. Cuentos sobre temas de la vida militar. Santiago de Cuba: Imprenta de Ravelo, 1895. Impreso.

Sariol, Juan Francisco. La muerte de Weyler. Manzanillo: El Arte, 1931. Impreso.

Serret, Alberto. Un día de otro planeta. Ciudad de la Habana: Letras Cubanas, 1986. Impreso.

Serret, Alberto. Consultorio terrícola. La Habana: Letras Cubanas, 1988. Impreso.

Soler, Rafael. Campamento de artillería. La Habana: Unión, 1975. Impreso.

Soler, Rafael. Noche de fósforos. La Habana: Unión, 1976. Impreso.

Tauler López, Arnoldo. La sangre regresada. La Habana: Unión, 1978. Impreso. 
Tauler López, Arnoldo. La cáscara del hombre. La Habana: Letras Cubanas, 1979. Impreso. Tauler López, Arnoldo. Cuentos de Seboruco. La Habana: Letras Cubanas, 1979. Impreso. Tauler López, Arnoldo. El caracol manchado. Santiago de Cuba: Caserón, 1987. Impreso. Torralbas, José Mariano. En busca del eslabón perdido. Santiago de Cuba: Caserón, 1989. Impreso.

Torralbas, José Mariano. La otra cara. Santiago de Cuba: Oriente, 1991. Impreso.

Torralbas, José Mariano. Señor de esperas. Santiago de Cuba: Renacimiento, 1995.

Torre, Augusto de la. En la Viña de/ Señor. La Habana: Casa de las Américas, 1984. Impreso.

Valle, Amir. Tiempo en cueros. La Habana: Universidad de La Habana, 1988. Impreso.

Valle, Amir. Yo soy el malo. La Habana: Letras Cubanas, 1989. Impreso.

Valle, Amir. En nombre de Dios. La Habana: Ediciones Unión, 1990. Impreso.

Valle, Amir. Brevísimas demencias. La Habana: Ediciones Extramuros, 2000. Impreso.

Valle, Amir. Manuscrito del muerto. La Habana: Letras Cubanas, 2000. Impreso.

Ventura Guerra, Rodolfo. Del símbolo y otros cuentos. Santiago de Cuba: Oriente, 1984. Impreso.

Ventura Guerra, Rodolfo. Variaciones. Santiago de Cuba: Oriente, 1988. Impreso.

Wong Subirat, Rubén. El último ángel de la memoria. Santiago de Cuba: Renacimiento, 1999. Impreso. 